ORIGINAL ARTICLE

\title{
The Womens' Attitude and Practice towrads Childbearing
}

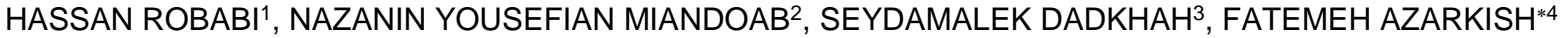 \\ ${ }^{1}$ Instructor of Community Health Nursing, Department of Nursing, School of Nursing and Midwifery, Pregnancy Health Research Center, \\ Zahedan University of Medical Sciences, Zahedan, Iran \\ ${ }^{2}$ Instructor of Medical -Surgical Nursing, Department of Nursing, School of Nursing and Midwifery, Community Health Research Center, \\ Zahedan University of Medical Sciences, Zahedan, Iran \\ ${ }^{3}$ Instructor of Medical -Surgical Nursing \\ Department of Nursing, School of Nursing and Midwifery \\ Iranshahr University of Medical Sciences, Iranshahr, Iran. \\ ${ }^{4}$ Assistant Professor of Reproductive Midwifery, Department of Midwifery, School of Nursing and Midwifery, Tropical and Communicable \\ Diseases Research Center, Iranshahr University of Medical Sciences, Iranshahr, Iran \\ Correspondence to Azarkish Fatemeh Email: Dr.azarkish@irshums.ac.ir
}

\begin{abstract}
Background: Fertility is one of the main components of population growth. Knowing the fertility level of any society is important in assessing the economic and social conditions.

Aim: To determine the attitude and practice of Zahedan women towards childbearing.

Methods: This descriptive-analytical study was performed on 400 Iranian married women aged 15-38 years in Zahedan. Data were analyzed by SPSS 11.5 software. Descriptive statistics methods and analytical statistics methods were used.

Results: The mean and standard deviation of the current number of the research units' children was $2.54 \pm 1.54$ children. Regarding the tendency to increase the number of children, $65.8 \%$ of women and $66 \%$ of their spouses tended to have another child and the average number of their preferred children was $3.49 \pm 1.44$. Other results showed that the majority of the subjects $(72.50 \%)$ had a moderate attitude towards childbearing.

Conclusion: Considering that more than half of women wanted to have another child and the majority of them had a moderate attitude towards childbearing, this shows a positive attitude toward childbearing. On the other hand, it should be noted that government interventions alone can not be a solution to prevent declining population growth, and in this regard, public acceptance and cooperation can also play an important role.

Keywords: Attitude, Performance, Childbearing, Women
\end{abstract}

\section{INTRODUCTIONS}

Fertility as one of the main components of population growth is an issue that has always been considered and extensive research has been done to identify the factors affecting it in Iran and abroad. In this regard, measuring and recognizing the fertility level in each class is necessary not only in population forecasts that are the basis of economic, social and demographic planning for development, but also in assessing the economic and social conditions of the study community it is also a major and important indicator.

In recent decades, our country has experienced many economic, social and demographic changes. Simultaneously with these changes and developments, reproductive behavior has also changed. Looking at the fertility situation of the whole country during the last three decades, it can be seen that the total fertility rate from 7 births per woman in 1979 has declined to 1.9 births in $2006^{1}$ and 1.6 births in 2011, which shows a sharp decline in fertility in the country over the past three decades ${ }^{2}$. Sistan and Baluchestan province once had the highest total fertility, but in 2009, its total fertility rate decreased to 3 children ${ }^{3}$.

According to statistics, in the last two decades, Sistan and Baluchestan province has had the highest annual population growth rate in the whole country, but from 2005 to 2008, we are witnessing a slight decreasing trend in the population rate of the province. In 1996, the household dimension in Sistan and Baluchestan province was 5.9 people, and in 2006, it declined to 5.1 people and with the continuation of the decreasing trend in 2011, the province's household dimension has declined to 4.3 people. Decrease in the household dimension indicates a decrease in the number of family members and as a result a decrease in fertility and childbearing ${ }^{4}$. In Iran, since the second half of 1980 s, fertility started reducing so that currently Iran is one of the countries with a low fertility level ${ }^{5}$. According to the results of the 2006 and 2011 censuses, the country is experiencing sub-replacement fertility levels ${ }^{1,2}$. If the situation continues in this way, we will face a major and fundamental challenge in terms of population in the future. Declining fertility to sub-replacement level and, consequently, declining population, increasing middle age population, followed by aging, and declining youth labor are among these challenges.

Decreased birth rate and fertility, in addition to having a decisive effect on the rate of population growth and thus decelerating the rate of increase in population, will also affect the composition and structure of the population. The continuous decline in births and the transfer from natural to controlled fertility gradually pushes the age structure of the population out of its youthful state toward aging. Therefore, the population pyramid of the population of Iran, which has always had a broad bottom throughout history and had a young structure in terms of concentration of more than $40 \%$ of the total population under the age of 15 , has changed in the last two decades due to reduced fertility and there is a depression at the bottom of the population pyramid. For this reason, the rate of the proportion below 15 years old has decreased from more than $45 \%$ in 1986 to a little value about $30 \%$ now, and in fact, in less than 20 years, it has 
been reduced to two thirds with an unprecedented trend. The trend of declining population under the age of 15 will continue for several decades and will reach about $20 \% 6$. Decreasing childbearing tendencies and changes in the behavior of women's reproductive ideals in addition to the decisive effect on population growth, will also affect the population composition and structure. Today, the decrease in the desire to have children, postponement of marriage, and as a result, the increase in the average age of marriage are included in the list of social issues in the country ${ }^{7}$. Based on the results of the general population and housing census in 2011, the average age of marriage for men and women in the country was 26.7 and 23.4 years, respectively, and is also increasing ${ }^{8}$.

In the last few decades, Iran has experienced various value and attitudinal changes in the field of fertility, marriage, and family ${ }^{10}$. A wide variety of economic, social, cultural, demographic, biological, and psychological factors affect fertility through complex mechanisms ${ }^{11}$. Among socio-economic factors, education has always shown its impact on reproductive behaviors as a strong factor ${ }^{12}$. In this regard, the results obtained from the study of Forouzanfar et al. (2012) also showed that reproductive behavior is influenced by the education and socioeconomic factors ${ }^{13}$.

The results of the study by Hosseini and Begi (2012) in Hamedan also indicated that the most important reasons for preferring the two-child model were economic problems and family problems in raising children. Other results showed that the probability of stopping childbearing is higher among employed women, those that have more alive children, those who perceive benefits of having children less than its costs, and are less inclined to prefer boys to girls ${ }^{10}$.

In addition to economic and social factors affecting fertility, religion can also explain some of the changes in fertility. Religion as a cultural factor affects fertility through norms related to family size, number of children and age of marriage, and norms related to intermediate variables ${ }^{14}$. In this regard, the results of the study of Kalantari et al. (2010) in Tabriz showed that social participation has a decreasing effect, but the variable of religious orientation has an increasing effect on the tendency of young people to have children ${ }^{15}$. Another factor affecting fertility is ethnicity. In this regard, the results of Shavazi and Sadeghi (2006) indicated that there is a significant relationship between ethnicity and fertility so that among the ethnic-linguistic groups in Iran, Baluchis had the highest and Gilaks had the lowest fertility level ${ }^{16}$.

Sistan and Baluchestan province in 2011 was the largest province in terms of geographical area and the tenth most populous province in the country, and women constitute $49.9 \%$ of the population of Sistan and Baluchestan province. In recent years, Iranian women have made undeniable progress in various fields of science, society, etc., including the women of this province ${ }^{4}$. Since the main key to gain power by women in various dimensions is literacy. Figures show that the trend of literacy of men and women in Sistan and Baluchestan province is progressing so that now the literacy rate in the province in the age group of 10 to 49 years, as the target group of literacy, has reached over $80 \%$ from $29 \%$ at the beginning of the revolution ${ }^{17}$.

During the last 15 years, the number of university graduates in the province has increased, so that in 1996, per every thousand women with a six-year literacy and higher, t15 women were university graduates, and per every thousand men with a six-year literacy and higher, 27 men were university graduate. In 2011, this ratio increased to 66 for men and 60 for women. The rate of economic participation of women in the province has increased in recent years, so that this rate has increased from $5.1 \%$ in 1996 to $8.8 \%$ in $2011^{4}$.

As the participation of women in the province in recent years in socio-economic activities has increased, these factors can empower women, making their role in decisions related to reproductive behaviors more powerful. In this regard, Hosseinbar (sociologist) explained the reason for the decrease in population in this province during 1996 to 2006 compared to the last decade as the increase of some social, educational and cultural indicators such as the development and increase of the academic community, the entry of people, especially women, into the labor market, particularly in administrative work, and raising the level of the public literacy ${ }^{18}$. Considering the demographic changes in the last decade and continuation of sub-replacement fertility, modification of demographic policies of the country had been considered by the policy makers and administrative and planning managers. In this regard, providing a birth incentive package is one of the main measures to prevent further reduction of fertility and increase it to the replacement level. Thus, the present study was conducted aiming at investigating the attitude and practice of Zahedan women towards childbearing and some related factors.

\section{MATERIALS AND METHODS}

This study is a descriptive-analytical study. The research population included all Iranian married women aged 15-38 years who had a health record in one of the health centers of Zahedan and referred there to receive maternal and child health services. In this study, multi-stage sampling method was used. Considering that Zahedan city had 40 health centers, first Zahedan city was divided into 4 regions: north, south, east, and west, and in the next stage, three centers in a total of 12 centers were randomly selected and then using convenience sampling method, the required number of samples was examined.

The data collection tool was an author-made questionnaire that was designed using different texts in this field. To ensure the validity of the questionnaire, the content validity was used. For this purpose, the opinions of 14 experts in this field (reproductive health, health education and nursing) were used and their opinions were applied in a questionnaire, so that out of 20 attitude items, 12 statements were approved. The reliability of the instrument was obtained using Cronbach's alpha coefficient (0.83). This questionnaire consisted of three parts. The first part asked about the personal characteristics of women (age, literacy, employment, etc.). In the second part, their childbearing performance and the factors influencing the desire and unwillingness to have children were asked, and 
in the third part, 12 items were asked about their attitudes toward childbearing. Attitude expressions were measured on a five-point Likert scale from strongly agree to strongly disagree.

Attitude expressions were scored by considering the direction of the expressions and then calculating the sum of their scores, so that in a question with a positive charge, a score of 5 was given for a strongly agree option and a score of 1 was given for a strongly disagree option. To facilitate the study report, the strongly agree and disagree sections, as well as the strongly disagree and disagree sections were merged. Attitude scores after scoring were placed in three levels of good, average, and poor. To describe the attitude status, considering that the minimum and maximum attitude scores of the subjects were 12 and 60 , respectively, contractually obtaining less points and equal to $50 \%$ of the total score represents a weak attitude $^{12-30}$, a score between $51-75 \%$ of the total score represents a moderate attitude ${ }^{31-45}$, and more than $75 \%$ of the total score was considered a good attitude ${ }^{46}$. In this method, obtaining higher scores indicates a more positive attitude towards childbearing. Data collection by direct interview with the eligible research units were performed in the health centers. The data were analyzed by SPSS 11.5. Descriptive statistics methods (mean and standard deviation and tables of absolute and relative frequency distribution) and analytical statistics methods (t-test, analysis of variance, Pearson correlation coefficient) were used.

\section{RESULTS}

Findings of this study showed that the mean age of the subjects was $28.02 \pm 5.59$ years and their mean age of marriage was $19.45 \pm 3.92$ years. The education of the majority $(26.8 \%)$ was secondary school education and the lowest percentage (10.5\%) was illiterate. The occupation of the majority $(87.3 \%)$ was housewife. Most of their spouses $(32.3 \%)$ had secondary school education and the lowest percentage $(7.8 \%)$ was illiterate. Their spouses were mostly self-employed (47\%) and the lowest number were employees (25.3\%). The ethnicity of the majority $(51.3 \%)$ was Baluch, and the majority of them (51.8\%) were Sunnis. Their average monthly income was 988.09 \pm 818.39 thousand Tomans. In terms of family relationship between husband and wife, 137 people (34.3\%) had no family relationship and $65.8 \%$ of them had close or distant family relationship. 269 people $(67.25 \%)$ used one of the contraception methods at the time of the study. The majority of the methods used $(40.89 \%)$ were condoms. The results showed that the majority of the studied units $(52.25 \%)$ had $1-2$ children at the time of the study and the average number of their current children was $1.54 \pm 2.51$ children.

Respondents were asked if they wanted to have another child in addition to their current children. In response to this question, $65.8 \%$ of women wanted to have another child and $66 \%$ of their husbands also wanted to have another child. The ideal number of children for $27.75 \%$ of the research units was $1-2$ children, 3-4 children for $57.5 \%$ of them, and 5 children and more for $14.75 \%$ of the research units. The average number of children desired by the respondents was $3.49 \pm 1.44$.

Out of 263 people who were interested in having another child, the most frequently cited reasons for wanting to have children were to achieve the desired number of children $(49.42 \%)$, to achieve gender balance of children $(19.01 \%)$, and fulfillment of the spouse's wish (11.40\%), and the least reasons were the belief that having children is beyond the control of the individual and is completely the God's will $(6.08 \%)$ and the government's incentive policies (1.14\%).

Of the 137 people who did not want to have another child, the most common reasons for not wanting to have children were lack of financial affordability $(37.22 \%)$, childbearing costs $(30.65 \%)$, and concern about the future of the child (17.51\%). The least common reasons were interference of childbearing with the interests, hobbies, work and education plans $(1.45 \%)$, spouse opposition $(2.18 \%)$, fear of childbirth and congenital anomalies of the child (2.91\%).

Findings on attitude showed that $66.25 \%$ of women believed that having children was useful for strengthening responsibility. $68.5 \%$ and $55.25 \%$, respectively, disagreed with the statements of "it is better to spend money on what I love instead of having child," "Having too many children is a sign of cultural and social backwardness". On the other hand, $60.75 \%$ believed that having too many children would limit their leisure time and educational and professional activities. $61.5 \%$ disagree the statement of "government incentive policies (Subsidies, increase in maternity leave, etc.) increase childbearing". Other results are presented in Table 1.

Other results regarding attitude towards childbearing showed that the majority of the research units $(72.50 \%)$ had a moderate attitude towards childbearing. $10.13 \%$ had a good attitude and $17.30 \%$ had a poor attitude. The overall mean score of the subjects was $37.10 \pm 6.79$ out of 60 .

Pearson correlation test showed that there is a significant negative relationship between the age of the subjects and their mean attitude score $(p=0.025)$ so that with increasing age of women, their attitude towards childbearing had decreased. There was a correlation between the average number of ideal children and their mean attitude score $(p=0.005)$ so that women who wanted more ideal children had a more positive attitude towards childbearing. Statistical tests did not show a significant relationship between the mean attitude score towards childbearing and other variables such as age of marriage, level of education, religion and ethnicity, and income.

With increasing women's education, the average number of desired ideal children had decreased from 4.66 in the illiterate group to 2.75 in the group with academic education, and the statistical test of analysis of variance showed a significant relationship between the level of education and the average number of desired ideal children $(p=0.001)$. With the increase in education of women's spouses, the average number of desired ideal children had decreased from 3.93 in the illiterate group to 2.89 in the group with academic education, and the ANOVA statistical test showed a significant relationship between the level of education and the average number of desired ideal children $(p=0.001)$. The average number of desired ideal children in housewife women was 3.56 and in employed women 
was 2.96 children, and the independent t-test showed a significant relationship between women's jobs and the average number of desired ideal children $(p=0.0005)$.

The average number of desired ideal children in women whose husbands were employees, workers and farmers, and self-employed were 2.85, 3.66, and 3.72 children, respectively $(p=0.001)$. The ANOVA statistical test showed a significant relationship between the husband job and the average ideal number of children $(p=0.001)$. The average ideal number of children in women of Persian ethnicity and Shiite religion was 2.94 and in women of Baluch and Sunni ethnicity was 4 children, and independent t-test showed a significant relationship between ethnicity and the average number of ideal children $(p=0.0001)$.

Table 1: Women's attitudes toward childbearing

\begin{tabular}{|c|c|c|c|c|c|c|}
\hline & \multicolumn{2}{|c|}{$\begin{array}{l}\text { Strongly agree and } \\
\text { agree }\end{array}$} & \multicolumn{2}{|c|}{ No idea } & \multicolumn{2}{|c|}{$\begin{array}{l}\text { Strongly disagree } \\
\text { and disagree }\end{array}$} \\
\hline & No. & Percent & No & Percent & No. & Percent \\
\hline 1. Childbearing is difficult and disturbs comfort of the couple & 170 & $42 / 5$ & 59 & $14 / 75$ & 171 & $42 / 75$ \\
\hline 2. Too many children reduce marital satisfaction & 162 & $40 / 5$ & 56 & $14 / 0$ & 182 & $45 / 5$ \\
\hline 3. Childbearing is useful for strengthening responsibility & 265 & $66 / 25$ & 65 & $16 / 25$ & 60 & $15 / 0$ \\
\hline 4. Too many children is contrary to health, vitality and youth & 111 & $27 / 75$ & 90 & $22 / 5$ & 199 & $49 / 75$ \\
\hline $\begin{array}{l}\text { 5. Having too many children restricts leisure time and academic and } \\
\text { professional activities }\end{array}$ & 243 & $60 / 75$ & 52 & $13 / 0$ & 105 & $26 / 25$ \\
\hline 6. Having many children increases family and ethnic power & 200 & $50 / 0$ & 72 & $18 / 0$ & 128 & $32 / 0$ \\
\hline 7. Restricting childbearing is contrary to religious beliefs & 129 & $32 / 25$ & 117 & $29 / 25$ & 154 & $38 / 5$ \\
\hline $\begin{array}{l}\text { 8. A large number of children is a sign of cultural and social } \\
\text { backwardness }\end{array}$ & 115 & $28 / 75$ & 64 & $16 / 0$ & 221 & $55 / 25$ \\
\hline 9. A large number of children is often blamed by others & 123 & $30 / 75$ & 53 & $13 / 25$ & 178 & $44 / 5$ \\
\hline $\begin{array}{l}\text { 10. It is better to spend money on something I love instead of on a } \\
\text { child }\end{array}$ & 88 & $22 / 0$ & 38 & $9 / 5$ & 274 & $68 / 5$ \\
\hline $\begin{array}{l}\text { 11. Government incentive support policies (subsidies, increase in } \\
\text { maternity leave, etc.) increase childbearing }\end{array}$ & 86 & $21 / 5$ & 68 & $17 / 0$ & 246 & $61 / 5$ \\
\hline $\begin{array}{l}\text { 12. Achieving the desired gender composition has an effect on } \\
\text { childbearing }\end{array}$ & 177 & $44 / 25$ & 97 & $24 / 25$ & 126 & $31 / 5$ \\
\hline
\end{tabular}

\section{DISCUSSION}

In the last half century, the fertility rate has decreased in most developing countries, but this declining trend in Iran has been very surprising. The dramatic decline in fertility rates has persuaded policymakers to change demographic policies and encourage couples to have children in recent years.

This study was designed and conducted in response to the question of whether a change in the country's population policies has led to an expected change in people's attitudes about their fertility. The results showed that $65.8 \%$ of women surveyed stated that in addition to having current children, they also want to have another child. The results of this study are inconsistent with some studies conducted in previous years in other parts of Iran, so that the results of Hosseini and Begi (2012) in Hamedan showed that $71 \%$ of the women surveyed stated that in addition to having their current children, they do not want to have another child ${ }^{10}$. Hosseini And Begi (2012) in their research in Mahabad concluded that $61.4 \%$ of women do not want to have another child other than the children they had at the time of the study ${ }^{19}$.

In another study in Urmia, Abbasi Shavazi showed that $60.4 \%$ and $62.6 \%$ of Kurdish and Turkish women, respectively, have no desire to have more children ${ }^{20}$. The results seem to be contradictory due to the different cultural context in the research environment.

According to the results, the ideal number of children in the majority of the subjects $(57.5 \%)$ was $3-4$ children, while the results of Hosseini and Begi (2012) in Hamedan showed that $78.4 \%$ of the respondents considered the desired number of children for families as two children ${ }^{10}$. In the study of Soroush and Bahrani in Shiraz (2013), 77.3\% of married women stated that the desired number of children was one to two ${ }^{21}$. The results of Hosseini and Begi (2012) in Mahabad also indicate the ideal number of two children in the study area, so that $6.69 \%$ of women stated that in the current situation of Iranian society the ideal number of children for a family is two children ${ }^{19}$. The average number of ideal children in the present study was 3.49. While in the study of Soroush and Bahrani in Shiraz (2013), the average number of ideal children was $2.12^{21}$. In the study of Farrokh Islamloo et al. in Urmia (2013), the average number of desired ideal children was 2.01 for men and 1.80 for women 22 .

In this study, with the increase in women's education, the average number of their ideal children decreased. Sadeghi in his study of socio-economic and demographic factors affecting fertility, showed that the higher level of education of couples reduces the number of children ${ }^{23}$. The study by Rajabi indicated that among the socio-economic indicators, women's education is one of the factors affecting fertility, and the women with a higher level of literacy give birth to fewer children ${ }^{24}$.

The increase in the level of education and the extensive entry of female students to universities in recent years in Iran has led to profound changes in the ideology and behavior of women, which some studies have introduced as an influential factor on female reproductive behavior. The findings by Abbasi Shavazi in Iran showed that the variable of women's education is the only variable that directly affects fertility rates ${ }^{25}$, because entering university and increasing education affect fertility level indirectly through changing individual attitudes and beliefs and forming modern attitudes and directly through raising the age of marriage and thus delaying the age of fertility.

Findings showed that the average number of ideal children in employed women is less than house wives, which is consistent with the study of Hosseini and Hosseini 
(2013). In this study, women who were employed had significantly lower fertility ${ }^{1}$. While in the study of Soroush and Bahrani (2013), the average number of ideal children in different employment situations did not differ significantly ${ }^{21}$. It seems that increasing women's education has led to more participation and presence of women in economic, social, and cultural issues of society. With the improvement of women's status and their position in society, women at home have more decision-making power in family affairs and as a result of these changes, their tendency to fertility has been reduced in order to maintain their position in society and in the family.

The findings showed that the average number of ideal children in women with Baluch and Sunni ethnicity is higher than women with Persian ethnicity and Shiite religion. This finding is also consistent with the results of studies by Abbasi Shavazi et al., which point to the high fertility of Sunni women in Sistan and Baluchestan ${ }^{26}$. The results of Mahmoudian and Nobakht (2010) in Galedar city of Fars province also showed that Sunni women have higher fertility $^{27}$. Zanjani and Naseri in the study of different groups of Turks, Baluch, Fars, Kurd, and Lor showed that there was a significant difference in fertility levels of ethnic groups under study ${ }^{28}$. However, it does not correspond to the results of Hosseini29, Ghorban Hosseini and Hatem Hassani ${ }^{1}$, and Maryam Soroush ${ }^{21}$. Some scholars explain these differences in relation to socio-economic conditions and contexts and not merely ethnic affiliation ${ }^{30}$. However, ethnicity as a cultural element is the context in which behavior is formed and ethnic belonging can influence the fertility behavior in different directions both through facilitating and strengthening the dissemination of new ideas related to fertility and through emphasizing the preservation of ethnic values and norms and preventing the acceptance of new ideas.

It seems that ethnic differences in fertility can be attributed to different levels of development and differences in socio-economic characteristics, especially education, in one hand, and resulting from culture, values, and specific ethnic beliefs, on the other hand.

In this study, it was found that the main reasons for not wanting to have children were lack of financial affordability and costs of having children, worries about the future of the child, and already having the desired number of children. Other researches are consistent with the results of our work, among which the study of Mobasheri et al. (2014) can be mentioned. In this study, the increase in living costs, economic pressure, and also the lack of government support and facilities have had an impact on the couple's childbearing ${ }^{31}$.

Findings on attitude showed that more than half of women believed that having children was useful for strengthening responsibility. $68.5 \%$ and $55.25 \%$, respectively, disagreed with the statements of "it is better to spend money on what I love instead of having child," "Having too many children is a sign of cultural and social backwardness". They believed that having too many children would limit their leisure time and educational and professional activities, and $61.5 \%$ disagree the statement of "government incentive policies (Subsidies, increase in maternity leave, etc.) increase childbearing".
While in the study of Mobasheri et al. (2014), 83.3\% of the subjects mentioned increasing costs and economic pressure, $45 \%$ mentioned spouse opposition, and $61.1 \%$ mentioned the belief of having more children as a sign of a weaker social culture as the obstacles for childbearing. About $30 \%$ believed that having children has interference with their job and that of their spouse and their education. On the other hand, $67.2 \%$ considered government support and welfare facilities to be effective on their fertility ${ }^{31}$. Overall, women's attitudes toward childbearing were moderate in the present study.

According to the results, the current number of children in the research units was 2.5 children, but more than half of women $(65.8 \%)$ also wanted to have another child, which shows a positive attitude concerning childbearing. Considering that the number of ideal children for the educated and employed women was fewer, it seems that improved position of women through education, social participation, and increased decision-making independence have caused reduction of childbearing attitudes. Many methods used to end post-term pregnancy including surgical, medicinal, and complementary methods which applied alone or in combination with each other. The most widely used methods are herbalism induction, homeopathy and acupuncture ${ }^{32}$. Regarding the importance of corporal \& psychic, physiological changes in women's life, it can be inferred that paying attention to psychic factors and dependency of our women society on medicinal treatments ${ }^{33}$. The rapid increase in population of working women over the past 20 years requires assessment of the effect of employment on reproduction. Workers of 20 million jobs are exposed to reproductive risks, mostly latent, with effects emerging years later (34). Higher education, and consequently the provision of job opportunities for women and employment outside the home, delays their marriage age and causes them to use contraception more than other women; This affects both the desires and fertility behavior of women. Equitable access to primary health care such as family planning and reproductive counselling, health literacy and environmental health are indispensable right and a basic need of all human beings. Currently, the development of any society is judged based on the level of public access to primary health care services ${ }^{35}$. Therefore, through proper management of active forces in society, including women, a sharp decline in fertility can be prevented. This is done by paying attention to family-centered policies.

\section{CONCLUSION}

Improving women's employment laws to better care for their children, providing affordable care services for the children of working and educated mothers, and paying attention to maternity leave and laws in this area help women combine maternal and social roles, and reduce the gap between these roles. In this case, women can engage in extracurricular activities such as education, employment, and social activities while caring for their children. On the other hand, it should be noted that government intervention alone cannot be a way to getting out the current problems, and in this regard, popular acceptance and cooperation can also play an important role. An integrated view of 
demographic problems and interventions in the most important factors affecting the fertility and childbearing of couples can open a clear perspective for the current demographic problem.

Acknowledgement: This study is financially and scientifically supported by the Vice-Chancellor for Research and Technology affiliated to Zahedan University of Medical Sciences. This paper has approved by Committee of Ethics by IRZAUMS.REC.1394.2/. and The code for proposal was 7241 . The authors also thank all the mothers who participated in this study.

Authors contribution: H.R, N.YM. and S.D. performed the measurements. S.D and F.A. were involved in planning and supervised the Work. H.R. and F.A. processed and performed the analysis, drafted the manuscript. $H . R$, N.YM, S.D entered data in SPSS and performed calculations. F.A and H.R interpreting the results(findings) and worked on the manuscript. All authors read the final manuscript, discussed the results and commented on It.

\section{REFERENCES}

1. 1.Hosseini Gh, Hosseini $H$. Comparing determinants of fertility behavior among Kurdish women living in rural areas of Ravansar and Gilangharb cities. Journal of Kermansha University of Medical Sciences, 2013(Issue 5)316-324

2. 2.United Nations, department of economic and social affairs, population division, population estimates and projections section .world population prospects, revision. [cited 20 June 2014]. Available at URL.http://esa.un.org/unpd/wpp/Excel-Data/fertility.htm

3. 3.National organization for civil registration. Category demographics ,2009(Persian).[cited 20 March 2013]. Available at URL. WWW.sabteahval.ir

/Upload/Modules/Conents/asset99/eteljamiyat88.pdf.

4. look at the status of women in Sistan and Baluchistan. (Persian). [cited $11 \mathrm{Jul}$ 2015]. Available at www.women.gov.ir/.../home/?

5. 5.Kalantari S, Mohammadi $\mathrm{H}$,Zareh shahabahi A. A study on demographic factors affecting fertility in Yazd(Persian).pazhuhis Zanan. 2005;3(2):137-56.

6. 6.Zanjani H. Demographic analysis, Tehran: samt. 2005

7. 7.Abbasi-Shavazi M, Askari-Nadoushan A.[Transformaton of family and fertility transition in Iran:case study in in Yazd province].(Persian).Journal of Social Science. 2005;11(3):25-75.

8. 8.Statistical center of Iran. Population and housing census in Iran 2011 (Persian). 2014: Available at http://www.amar.org.ir/. Access data : $15 / 06 / 2014$

9. 9.Bay J.[Reason for lack motivation young couples to childbearing (Persian).2014: Available at http://tabesh.net/,Access data : 10/06/2014

10. Husseini H, Bagi B. Socioeconomic, cultural and demographic determinants of childbearing desires among married women attending health centers in Hamedan Journal of Kermanshah University of Medical Sciences.2012:18(1):35-43

11. One-child injuries. (Persian).2014: Available at http:// www.parsnews.com/.../77460.Access data: 15/06/2014.

12. 12.Abbasi-Shavazi M, Chavoshi M. unwanted pregnancy and effective factors on it Iran. Journal of fertility and infertility.2003:5(1):62-67

13. Forouzanfar S, Maglesi F, Rahimi A, Pour- Reza A. Examine the relationship Empowerment of Women of reproductive behavior. Bimonthly Scientific - Research of Shahed University. 2011:19 (99): 1-

14. Mahmudian H, Noubakht R. Religion and Fertility: Analysis of Behavior childbearing religious groups sonny and shieh on ghalledar city in the Fars province. Social issues in Iran.2009;1(1); 195-215
15. 15.Kalantari S, Abbaszadeh M, Mozaffari F M, Raky N. The Sociological Study of Attitude to Child bearing and it's some related Journal of Applied Sociology. 2010; 21 (1) :83-104

16. 16.Shavazi MJ, Sadeghi R. Ethnicity and Fertility: analysis of reproductive behavior in ethnic groups in Iran. A social science.2006; (19): $29-58$

17. Sistan and Baluchestan. (Persian). [cited 5 Jul 2015]. Available at. http://www.nasimonline.ir/detail/News/955022/211

18. Sistan and Baluchistan. (Persian). [cited 11 Jul 2015]. Available at. http://www1.jamejamonline.ir/newstext2.aspx?newsnum $=1008593191$ 00

19. 19.Hosseini H. Bagi B. Women's Independence and Fertility Activities Among Kurdish Women in Mahabad. Woman in Development and Politics. 2012: 10(4).57-78.

20. Abbasi Shavazi MJ. Ethnicity and Fertility: Testing Competing Hypotheses to Explain Ethnic Differences in Fertility in the city of Urmia. http://populationstudies.blogfa.com/post-26.aspx

21. Soroush M.Bohrani sh .Relationship between religiosity, attitude toward gender roles and attitude toward the child,With the real number and ideal of the child. Women's publication in development and politics. 2013:11(2). $208-189$.

22. Farrokh-Eslamlou HR, Vahabzadeh Z, Moeini SR, Moghaddam Tabrizi F.22

23. Pre-marriage couples Fertility Attitude Following recnet Childbearing Persuasive policies in Iran. The Journal of Urmia Nursing and Midwifery Faculty. 2013: 11(10).836-846

24. 23.Sadeghi Mirmohammad. Effective Socio-economic and demographical factor on reproduction in rural areas of Najafabad. $J$ research of women. $2010: 8(1) 28.143-159 ;$ [cited 1012 Jul 18] Available at http://www.Sid.ir/fa/. Access data: 15/06/2014

25. 24.Rajabee. Mahrokh. The rol of women situation on reproductive behavior in shiraz. Iran Demography Assciation ;2010 april 26. Available at http://www. Demography.ir/Category /population -html

26. 25.Abbasi Shawazi MJ. Ali Mandgari M. The effect of different dimensions of women's independence on Their Fertility Behavior in Iran ", Women's Research. 2010. 8(1)32-51

27. 26.Abbasi-Shavazi M, Husseini-Chavoshi M. [ fertility transition in Iran.the evidences from four selected province].(Persian). $1^{\text {st }}$ ed.Tehran: Ministry of Health and Medical Eduaction .2004:30-40

28. Mahmudian H. Nobokht R. Religion and fertility. Analysis of the Behavioral Exertion of Sunni and Shieah Religious Groups in Fars Province. Social Issues of Iran. 2010.1(1).195-215

29. 28.Zanjani H. Naseri MB. The study of ethnic differences and their impact on the fertility of women in Iran. 1996. The joint project of UNESCO and the Population Section of Iran's Center for Urban Planning and Architecture.

30. Husseini $\mathrm{H}$. Asurvey of the effect of soio-economic and demographical factor on fertility in rural areas of Ghorveh.].(Persian) .Ssecond conference of the Iranian association of population . shiraz University.2014.425-6.

31. 30.Hosseinzadeh AH. Noohjah S. Sharifi M. Investigating the Fertility Pattern of Marriage Age and the Use of Regulatory Family Planning Methods among different ethnic groups of Ahwaz city in 2009. Specialized Journal of Social Sciences Islamic Azad Shoushtar University.2010.4(8)67-96

32. 31.Mobasheri1 M. Alidousti M. Heidari Soureshjani S. Khosravi F. Khalafeyan $P$. Jalilian $M$. Determination of the Most Important Factors Influencing the Fertility Patterns of Single Child and Without Child Families in Shahr-e-kord City in 2013. Scientific Journal of Ilam University of Medical Sciences,2013, 21(6):63-70.

33. Teimoori B., Navvabi-Rigi Sh., Rajabi Sh., Arbabisarjou A. Global Journal of Health Science; 2015:,7( 3):177-183.

34. Sakhavar N.,Teimoory B, Razavi M., Mirteimoori, M., Arbabisarjou, A. Ghaljeh M. The effect of Vitagnus on treatment of hot flash in menopause. Life Sci J2013;10(1):628-632.

35. 34. Khojasteh F. , Arbabisarjou A., Boryri B, Safarzadeh A., Pourkahkhaei M., The Relationship between Maternal Employment Status and Pregnancy Outcomes, Global Journal of Health Science; 2016:,8( 9): 37-43.

36. Sarani M., Arbabisarjou A., Saravani S., Niri A., Shahrakivahed A., Effect of the Implementation of the Family Physician Program 2015 on Fair Accessibility for People to Health Care Services in the Sistan Region, Global Journal of Health Science; 2016:,8( 12): 20-26. 